\title{
Concentration effects of Winogradskyella sp. on the incidence and severity of amoebic gill disease
}

\author{
Sridevi Embar-Gopinath*, Philip Crosbie, Barbara F. Nowak \\ School of Aquaculture and Aquafin CRC, University of Tasmania, Locked Bag 1370, Launceston, Tasmania 7250, Australia
}

\begin{abstract}
To study the concentration effects of the bacterium Winogradskyella sp. on amoebic gill disease (AGD), Atlantic salmon Salmo salar were pre-exposed to 2 different doses $\left(10^{8}\right.$ or $10^{10}$ cells $\mathrm{l}^{-1}$ ) of Winogradskyella sp. before being challenged with Neoparamoeba spp. Exposure of fish to Winogradskyella sp. caused a significant increase in the percentage of AGD-affected filaments compared with controls challenged with Neoparamoeba only; however, these percentages did not increase significantly with an increase in bacterial concentration. The results show that the presence of Winogradskyella sp. on salmonid gills can increase the severity of AGD.
\end{abstract}

KEY WORDS: Neoparamoeba - Winogradskyella · Amoebic gill disease · AGD · Gill bacteria · Bacteria dose $\cdot$ Salmon disease

\section{INTRODUCTION}

Amoebic gill disease (AGD) in Atlantic salmon Salmo salar L. is one of the significant problems faced by the south-eastern aquaculture industries in Tasmania. The causative agent of AGD is Neoparamoeba spp. (reviewed by Munday et al. 2001, Dykovà et al. 2005). Although extensive research of bacterial (Sawyer 1978, Rintamaeki \& Valtonen 1991, Cipriano et al. 1992, Ford et al. 1998, Valheim et al. 2000) and amoebic disease (reviewed by Munday et al. 2001, Adams \& Nowak 2004, Dykovà et al. 2005) in Atlantic salmon has been conducted, only a few studies have attempted to examine the association between salmonid gill bacteria and AGD. Bowman \& Nowak (2004) assessed the bacterial communities of salmon gills using culture-independent $16 \mathrm{~S}$ ribosomal RNA analyses and suggested that bacteria from the genus Psychroserpens, which were only detected on AGDaffected fish gills, might be linked to AGD. A recent 16S rRNA gene-based study identified the culturable gill bacteria in AGD-affected salmonids and demonstrated that the gills were predominantly colonised by bacteria that had biochemical profiles similar to those of Winogradskyella spp. (strains $\mathrm{AC} 1, \mathrm{AC} 2$ and $\mathrm{BC} 1$; Embar-Gopinath et al. unpubl.).
Winogradskyella is a recently established genus within the family Flavobacteriaceae, and currently contains 4 recognised members: $W$. thalassicola, $W$. epiphytica and $W$. eximia isolated from algal frond surfaces in the Sea of Japan (Nedashkovskaya et al. 2005), and $W$. poriferorum isolated from the surface of a sponge in tropical water (Lau et al. 2005). There is no further information available on the development and effects of Winogradskyella spp. on any organism; therefore, it is currently considered non-pathogenic. The Winogradskyella sp. strains AC1, AC2 and BC1 isolated from AGD-affected salmonid gills during our previous research have gene sequence similarities of 95.1\% (AC1), $96.6 \%(\mathrm{AC} 2)$ and $95.2 \%(\mathrm{BC} 1)$ to $W$. poriferorum; $96.6 \%$ (AC1), 96.9\% (AC2) and 96.8\% (BC1) to $W$. eximia; $95.6 \%$ (AC1), 96.4\% (AC2) and $96.1 \%$ (BC1) to $W$. thalassocola; and $96.1 \%$ (AC1), $96.6 \%$ (AC2) and $96.3 \%$ (BC1) to $W$. epiphytica (Embar-Gopinath et al. unpubl.). These strains (AC1, $\mathrm{AC} 2$ and $\mathrm{BC} 2$ ) are probably new species of the genus Winogradskyella, because the strains have a sequence homology value of $<99 \%$ with the type strains (Bosshard et al. 2003).

Recent experiments conducted to study the influence of bacteria in the development and severity of AGD showed that fish experimentally infected with Wino- 
gradskyella sp. strain AC1 developed increased numbers of gill lesions following Neoparamoeba spp. infection (Embar-Gopinath et al. 2005a). The present experiment aimed to study the concentration effects of this bacterium on AGD.

\section{MATERIALS AND METHODS}

Experimental design and $\mathrm{KMnO}_{4}$ treatment. Atlantic salmon Salmo salar L. ( $=72$; mean weight $=115 \mathrm{~g}$ ) were acclimatised to sea water $(30 \%, 2 \mu \mathrm{m}$ filtered) over 2 wk in 40001 tanks connected to individual biofilters. Subsequently, fish were transferred using dipnets from recirculation tanks to individual static tanks for a short-term bath (20 min) in potassium permanganate (5 mg $\mathrm{KMnO}_{4} \mathrm{l}^{-1}$ ) to remove the natural microflora on the gills; this treatment was shown to reduce the gill bacterial levels with no adverse effects to Atlantic salmon (Embar-Gopinath et al. 2005b). After $\mathrm{KMnO}_{4}$ treatment, fish were transferred to 6 identical recirculating systems each consisting of three $70 \mathrm{l}$ tanks ( $\mathrm{n}=4$ fish per tank) and a $70 \mathrm{l}$ reservoir and acclimated to salinity $35 \%$ over a period of $2 \mathrm{~d}$. Sea water temperature was maintained at $16 \pm 0.5^{\circ} \mathrm{C}$, $\mathrm{pH}$ 8.2, dissolved oxygen $7.5 \mathrm{mg} \mathrm{l}^{-1}$ and total ammonianitrogen below $0.2 \mathrm{mg} \mathrm{l}^{-1}$. Sufficient aeration was maintained in the tanks throughout the experiment by use of aerators.

Treatment groups. Following acclimatisation of fish, the 6 recirculation systems were assigned to 3 treatment groups (2 systems per treatment consisting of 3 tanks with 4 fish each). Each treatment was conducted in duplicate. Fish in Group 1 were exposed to Neoparamoeba spp. only (positive control), those in Group 2 to Winogradskyella sp. strain AC1 $\left(10^{8}\right.$ cells $\left.1^{-1}\right)$ and Neoparamoeba spp., and those in Group 3 to Winogradskyella sp. strain AC1 $\left(10^{10}\right.$ cells $\left.1^{-1}\right)$ and Neoparamoeba spp.

Neoparamoeba spp. isolation. Neoparamoeba spp. were harvested from AGD-affected Atlantic salmon held at the Aquaculture Centre, University of Tasmania, Launceston by a method described by Morrison et al. (2004) modified by addition of antibiotic and antimycotic solution [(5\% v/v $5000 \mathrm{IU} \mathrm{m}^{-1}$ penicillin and $5 \mathrm{mg} \mathrm{ml}^{-1}$ streptomycin solution [Sigma], $1 \% \mathrm{v} / \mathrm{v}$ $10 \mathrm{mg} \mathrm{ml}^{-1}$ gentamycin [Sigma] and $0.25 \mathrm{mg} \mathrm{ml}^{-1}$ amphotericin B [Invitrogen]) in order to eliminate bacteria/fungi from the amoebae inoculum (Butler \& Nowak 2004, Embar-Gopinath et al. 2005a).

Bacteria cultivation and characterisation. Cryopreserved samples of Winogradskyella sp. strain AC1 previously isolated from AGD-affected fish gills (EmbarGopinath et al. unpubl.) were cultured in marine Sheih's broth (Song et al. 1988) modified by the addi- tion of seawater and omission of the trace element supplement. Briefly, the bacteria were revived using starter cultures $(4 \times 500 \mathrm{ml}$ broth) that were placed on an orbital mixer (Ratek Instruments) and rotated at 3 to $4 \mathrm{rpm}$ for $24 \mathrm{~h}$ at $22^{\circ} \mathrm{C}$. Broths containing the bacteria were then pooled and transferred to an aerated $3 \mathrm{l}$ carboy and incubated for a further $48 \mathrm{~h}$ at $22^{\circ} \mathrm{C}$. The resultant bacterial cells were washed and mixed with suitable volumes of sea water to obtain desired challenge doses. The viability of the cells was tested using trypan blue exclusion assay (Phillips 1973). Aseptic conditions were adapted throughout the entire process of bacteria culture. For identification purposes, the cells were grown on marine Sheih agar and the colony morphology and enzymatic activity (API Zym, bioMérieux Australia) of Winogradskyella sp. strain AC1 were recorded. Briefly, Winogradskyella sp. are Gram negative, rod shaped cells, with an approximate cell length of $0.86 \mu \mathrm{m}$ and cell width of $0.39 \mu \mathrm{m}$. Colonies are yellow pigmented, entire and translucent with low convex elevation and are $2 \mathrm{~mm}$ in length. The API Zym test shows that Winogradskyella sp. metabolises alkaline phosphatase, esterase lipase (C8), $\alpha$-chymotrypsin, leucine arylamidase, valine arylamidase, acid phosphatase and napthol-AS Bl phosphohydrolase.

Bacteria and amoebae exposure. Fish in Groups 2 and 3 were inoculated with Winogradskyella sp. by means of a bath treatment for $1 \mathrm{~h}$. Briefly, fish were transferred using individual nets from the recirculating systems into 2 static tanks filled with sea water (salinity $35 \%$ ) and containing bacteria at concentrations of $10^{8}$ and $10^{10}$ cells $1^{-1}$ respectively. Group 1 fish were handled in the same manner but were bathed in sea water only. All fish were returned to their respective systems and were maintained for $4 \mathrm{~d}$ to allow the development of inoculated colonies on the gills. All groups were then infected with Neoparamoeba spp. at a concentration of 300 cells $1^{-1}$.

Day 0 sampling. Immediately prior to Neoparamoeba spp. inoculation, a sub-sample of 6 fish from each group were euthanased by Aqui-S ( $2 \% \mathrm{v} / \mathrm{v})$, and the second left gill arch and anterior kidney were gently swabbed and inoculated onto marine Sheih's agar and incubated at $22^{\circ} \mathrm{C}$ for $48 \mathrm{~h}$. After swabbing for bacteriology, all gills were removed and placed in sea water Davidson's fixative for $12 \mathrm{~h}$, then post-fixed in $70 \%$ ethanol to assess gill damage possibly caused by Winogradskyella sp. exposure. The second right gill arch was wax-embedded, and $5 \mu \mathrm{m}$ sections were cut and Gram-stained. All sections were viewed under light microscope at magnifications ranging from $\times 10$ to $\times 1000$ (Olympus).

Day 8 sampling. The experiment was terminated and fish from all groups were sampled on Day 8 postamoebae challenge when white mucous patches (con- 
sistent with AGD gross pathology) were observed on the gills of the treatment groups. Fish were euthanased and samples were collected for bacteriology and histology as described above. To diagnose AGD, $5 \mu \mathrm{m}$ sections of the second right gill arch was stained with haematoxylin and eosin (H\&E). All sections were viewed by a light microscope (Olympus) at 40 to $400 \times$ magnification, and fish with typical AGD lesions characterised by a single or multifocal epithelial hyperplasia of the gill lamellae, focal fusion of secondary lamellae and round to ovate interlamellar vesicles containing amoeba were considered AGD-positive. To quantify AGD severity, the number and size of AGD lesions were estimated as described by Adams \& Nowak (2001). The percentage of filaments with lesions was determined by estimating the ratio of filaments with AGD lesions to filaments with no AGD lesions. Lesion size was analysed by counting the number of hyperplastic interlamellar units within each lesion. Images of the affected tissue were taken using a Leica DC300f digital camera.

Winogradskyella sp. retrieval. To confirm the presence of Winogradskyella sp. strain AC1, culture plates were examined and colonies that had similar morphology, Gram characteristics and size to Winogradskyella sp. strain AC1 were selected. API Zym profile matched with those of Winogradskyella sp. strain AC1.

Statistical analysis. A 1-way ANOVA using SPSS version 11.5 was performed to test for significant differences in AGD severity. Significant differences among groups were assessed using Tukey's Honestly Significant Difference (HSD) post hoc test. The homogeneity of variance was assessed using Levene's test of equality of error variances. Differences were considered significant at $\mathrm{p}<0.05$.

\section{RESULTS}

\section{Bacteriology}

Winogradskyella sp. strain AC1 was retrieved from all fish in Groups 2 and 3 (exposed to Winogradskyella sp. at $10^{8}$ and $10^{10}$ cells $\mathrm{l}^{-1}$, respectively, prior to amoebae challenge) on both sampling days, i.e. on Day 0 (before Neoparamoeba spp. exposure) and Day 8 (8 d post Neoparamoeba spp. exposure). Furthermore, fish from both groups had clusters of bacteria in their interlamellar space, which could be seen in histological sections (Fig. 1a). Despite the fact that some bacteria were isolated from the group that was not exposed to Winogradskyella sp. (Group 1), the colony morphology, cell shape and size and enzymatic profiles of these bacteria were not consistent with those of Winogradskyella sp. strain AC1. None of the fish exposed to Winogradskyella sp. had signs of pathology prior to AGD: histological examination conducted on Day 4 post-exposure confirmed the gills of Group 2 and 3 fish to be normal and healthy. No bacterial growth was detected on the culture plates from the kidney swabs collected from Groups 1, 2 and 3 on any sampling day.
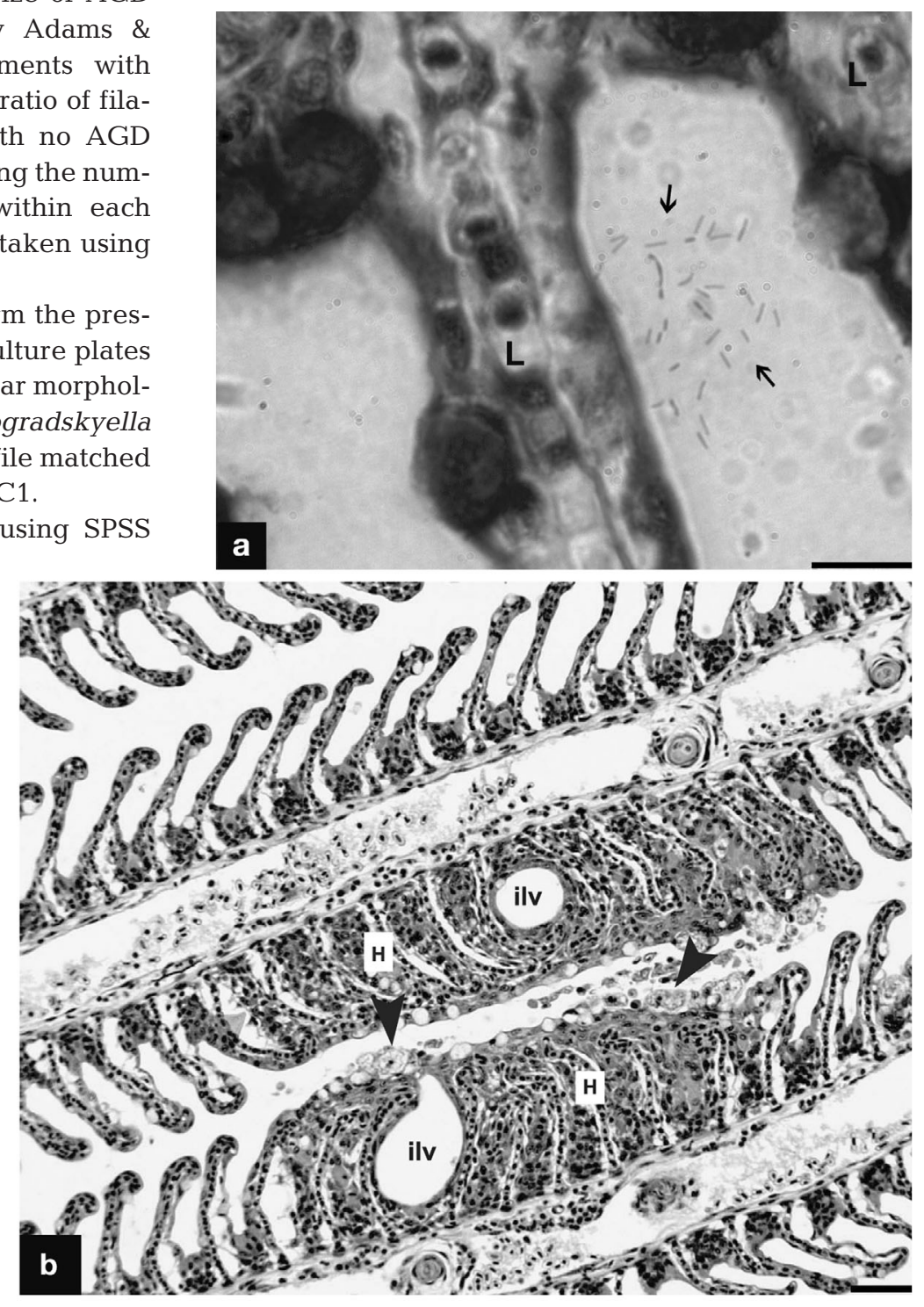

Fig. 1. Salmo salar. (a) Gill section of amoebic gill disease (AGD)-affected Atlantic salmon. Rod-shaped Winogradskyella sp. (arrows) appears scattered in the interlamellar space adjacent to the gill lamellae (L). Scale bar $=10 \mu \mathrm{m}$. (b) Gill section showing severe AGD infection characterised by a row of amoebae (arrowheads) on the hyperplastic lamellar $(\mathrm{H})$ surface and the occurrence of interlamellar vesicles (ilv). Scale bar $=50 \mu \mathrm{m}$ 


\section{Assessment of AGD}

Histological examination of gill sections showed that fish in Groups 1, 2 and 3 displayed typical AGD lesions characterised by diffusion of primary and secondary lamellae, occurrence of continuous rows of Neoparamoebae on the surface of hyperplastic lamellae and presence of interlamellar vesicles, multifocal necrosis and mononuclear cell infiltration (Fig. 1b). There were no apparent differences in AGD lesion structure among the 3 treatment groups. A significant difference in the percentage of filaments with lesions was noted between the fish previously exposed to Winogradskyella sp. (Groups 2 and 3 ) and the fish with no Winogradskyella sp. exposure (Group 1) prior to Neoparamoeba spp. infection $(F=10.6$, df $2,51, \mathrm{p}<0.001$; Fig. 2). However, there was no significant difference in the percentage of affected filaments between groups that were exposed to Winogradskyella sp. at concentrations $10^{8}$ and $10^{10}$ cells $1^{-1}$ (Fig. 2); approximately $21 \%$ of Group 2 and $17 \%$ of Group 3 gill filaments bore lesions. Also, there was no significant difference in lesion size among all groups (1,2 and 3); lesion size averaged from 18 to 24 interlamellar units (Fig. 2). In all cases, no significant differences between replicates within treatments were observed.

\section{DISCUSSION}

This study demonstrated that fish previously exposed to Winogradskyella sp. at concentrations of $10^{8}$ and $10^{10}$ cells $1^{-1}$ prior to Neoparamoeba spp. infection

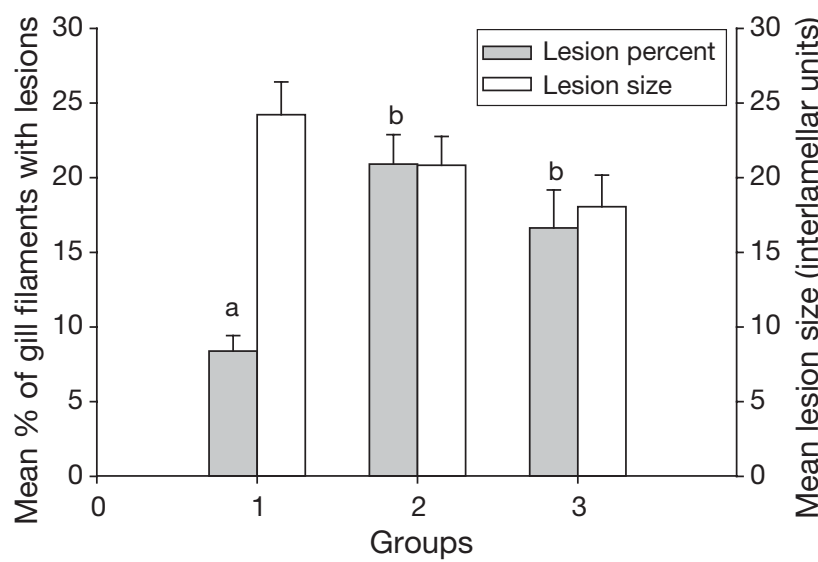

Fig. 2. Mean $\pm \mathrm{SE}$ percentage of filaments with lesions and number of infected lamellae within each lesion in treatment groups. Group 1: Neoparamoeba sp. only; Group 2: Wino-

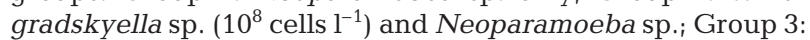
Winogradskyella sp. $\left(10^{10}\right.$ cells $\left.\mathrm{l}^{-1}\right)$ and Neoparamoeba sp. Separate analyses were conducted for lesion percentage and lesion size. Different letters above error bars indicate that groups differ significantly had significantly higher percentage of filaments with lesions compared with fish not exposed to Winogradskyella sp.. Similarly, our previous research (EmbarGopinath et al. 2005a) recorded a significant increase in the percentage of affected filaments in fish that were inoculated with $10^{8}$ cells $\mathrm{l}^{-1}$ of Winogradskyella sp. prior to amoebae exposure compared with fish with no Winogradskyella sp. inoculation. Furthermore, neither study found significant differences in lesion size (number of interlamellar units within each lesion) among treatment groups. However, in spite of these similarities, the percentage of affected filaments and lesion size varied between experiments. In the present experiment, approximately $21 \%$ of filaments from Group 2 (exposed to $10^{8}$ cells $1^{-1}$ of Winogradskyella sp.) bore AGD lesions, in comparison to the previous study where the proportion of AGD-affected filaments was approximately $51 \%$ in fish exposed to the same concentration of Winogradskyella sp. (Embar-Gopinath et al. 2005a). At the same time, AGD lesion size averaged between 2 and 4 interlamellar units in the previous study (Embar-Gopinath et al. 2005a), whereas it averaged between 18 to 24 interlamellar units in the present study. Thus, although we noted a similar trend in both studies, the numbers were not identical. We suppose that the reasons for these differences might be due to dissimilarities in fish population, because the previous experiment (Embar-Gopinath et al. 2005a) was conducted with winter smolts whereas the present experiment was conducted with summer smolts. Furthermore, due to unavailability of fish, smolts of the present experiment were procured from a different farm. In addition, the disparity might also have resulted from differences in amoebae isolates: variation in AGD pathology induced by amoebae isolated at different times has been previously noted (P. Crosbie unpubl. data).

There was no significant difference in the percentage of AGD-affected filaments between fish treated with either concentration of Winogradskyella sp. (i.e. between Groups 2 and 3) prior to amoebae infection. A similar lack of dose-related response was reported in a study involving experimental induction of bacterial kidney disease in Chinook salmon via immersion of fish in various concentrations of Renibacterium salmoninarum cells $\left(10^{4}\right.$ to $10^{6} \mathrm{ml}^{-1}$ ) (Murray et al. 1992). We did not determine whether there was a higher abundance of Winogradskyella sp. on Group 3 than on Group 2 on Day 4 post-inoculation; however, we assumed it to differ and hypothesise 4 possible reasons for the lack of a dose-related response: firstly, the difference in bacterial concentration range (100-fold) selected for bath exposure was not large enough to lead to a noticeable difference in the severity of AGD; secondly, the increase in the concentration of Wino- 
gradskyella sp. in Group 3 might have increased the number of Winogradskyella sp. on the gills, thus restricting the gill surface area required for amoebae colonisation; thirdly, the rate of progression of AGD may reach a threshold beyond which the disease cannot develop any faster; fourthly, $4 \mathrm{~d}$ after inoculation, the difference in Winogradskyella sp. number may be much less substantial (e.g. owing to proliferation within the smaller population and placement of growth constraints on the larger population) than at the time of inoculation.

In conclusion, this study found that the severity of AGD does not increase with an increase in concentration of Winogradskyella sp., i.e. exposure of Atlantic salmon Salmo salar to either $10^{8}$ or $10^{10}$ cells $1^{-1}$ does not cause a significant difference in the percentage of AGD-affected filaments. Nevertheless, this study reconfirmed that the presence of Winogradskyella sp. strain AC1 on the salmonid gills may result in more severe AGD. This suggests that Winogradskyella sp. has some effect on Atlantic salmon and AGD. Meanwhile, this study recorded that Winogradskyella sp. strain AC1 does not cause any pathology in Atlantic salmon during the first $4 \mathrm{~d}$ of its exposure. However, we do not know the pathogenicity of this strain beyond Day 4, because this experiment did not include a treatment group that was exposed to Winogradskyella sp. alone. Furthermore, the physiological effect of this bacterium on Atlantic salmon is unknown. Further research is required to examine the pathogenic effect of Winogradskyella sp. on Atlantic salmon over a prolonged incubation period. In addition, it is also important to study the influence of Winogradskyella sp. on the physiological condition of Atlantic salmon.

Acknowledgements. We acknowledge R. Mehta and T. Subramanian for their support during sample collection and $\mathrm{M}$. Attard for help with fish acclimation and fish transfer. We acknowledge the Australian Government for an Australian Postgraduate Award to S.E.G. This study formed part of a project of Aquafin $\mathrm{CRC}$, and received funds from the Australian Government's CRCs programme, the Fisheries R\&D Corporation and other CRC participants.

\section{LITERATURE CITED}

Adams MB, Nowak BF (2001) Distribution and structure of lesions in the gills of Atlantic salmon, Salmo salar L., affected with amoebic gill disease. J Fish Dis 24:535-542 Bowman JP, Nowak B (2004) Salmonid gill bacteria and their

Editorial responsibility: Dieter Steinhagen,

Hannover, Germany relationship to amoebic gill disease. J Fish Dis 27:483-492 Butler R, Nowak BF (2004). In vitro interactions between Neoparamoeba sp. and Atlantic salmon epithelial cells. J Fish Dis 27:343-349

Bosshard PP, Abels S, Zbinden R, Bottger EC, Altwegg M (2003) Ribosomal DNA sequencing for identification of aerobic gram-positive rods in the clinical laboratory (an 18 month evaluation). J Clin Microbiol 41:4134-4140

Cipriano RC, Ford LA, Teska JD, Hale LE (1992) Detection of Aeromonas salmonicida in the mucus of salmonid fishes. J Aquat Anim Health 4:114-118

Dyková I, Nowak BF, Crosbie PBB, Fiala I, Peckova H, Adams MB, Machackova B, Dvorakova H (2005) Neoparamoeba branchiphila n. sp., and related species of the genus Neoparamoeba Page, 1987: morphological and molecular characterization of selected strains. J Fish Dis 28:49-64

Embar-Gopinath S, Butler R, Nowak B (2005a) Influence of salmonid gill bacteria on development and severity of amoebic gill disease. Dis Aquat Org 67:55-60

Embar-Gopinath S, Crosbie PBB, Nowak B (2005b) Use of potassium permanganate to disinfect Atlantic salmon (Salmo salar) gills. Bull Eur Assoc Fish Pathol 25:291-29

Ford LA, Barbash PA, Cipriano RC (1998) Control of furunculosis and enteric redmouth disease in sea-run Atlantic salmon broodstock in the Connecticut and Merrimack Rivers. Prog Fish-Cult 60:88-94

Lau SCK, Tsoi MMY, Li X, Plakhotnikova I and 6 others (2005) Winogradskyella poriferorum sp. nov., a novel member of the family Flavobacteriaceae isolated from a sponge in the Bahamas. Int J Syst Evol Microbiol 55:1589-1592

Morrison RN, Crosbie PB, Nowak BF (2004) The induction of laboratory-based amoebic gill disease revisited. J Fish Dis $27: 445-449$

Munday BL, Zilberg D, Findlay V (2001) Gill disease of marine fish caused by infection with Neoparamoeba pemaquidensis. J Fish Dis 24:497-507

Murray CB, Evelyn TPT, Beacham TD, Barner LW, Ketcheson JE, Prosperi-Porta L (1992) Experimental induction of bacterial kidney disease in Chinook salmon by immersion and cohabitation challenges. Dis Aquat Org 12:91-96

Nedashkovskaya OI, Kim SB, Han SK, Snauwaert C and 8 others (2005) Winogradskyella thalassicola gen. nov., sp. nov., Winogradskyella epiphytica sp. nov. and Winogradskyella eximia sp. nov., marine bacteria of the family Flavobacteriaceae. Int J Syst Evol Microbiol 55:49-55

Phillips HJ (1973) Dye exclusion test for cell viability. In: Kruse PF, Patterson MK (eds) Tissue culture methods and applications. Academic Press, New York, p 406-408

Rintamaeki P, Valtonen ET (1991) Aeromonas salmonicida in Finland: pathological problems associated with atypical and typical strains. J Fish Dis 14:323-331

Sawyer ES (1978) Vibriosis in Maine and New Hampshire salmonids. Mar Fish Rev 40:9-10

Song YL, Fryer JL, Rohovec JS (1988) Comparison of six media for the cultivation of Flexibacter columnaris. Fish Pathol 23:91-94

Valheim M, Haestein T, Myhr E, Speilberg L, Ferguson HW (2000) Varracalbmi: a new bacterial panophthalmitis in farmed Atlantic salmon, Salmo salar L. J Fish Dis 23:61-70

Submitted: May 24, 2006; Accepted: August 24, 2006

Proofs received from author(s): November 7, 2006 